\title{
Relation between phalangeal bone mineral density and radiographic knee osteoarthritis: a cross-sectional study
}

\author{
Zhen-han Deng ${ }^{1 \dagger}$, Chao Zeng ${ }^{1 \dagger}$, Yu-sheng $\mathrm{Li}^{1}$, Tuo Yang ${ }^{1}$, Hui Li ${ }^{1}$, Jie Wei ${ }^{2,3}$ and Guang-hua Lei ${ }^{1 *}$
}

\begin{abstract}
Background: Major reports have suggested that bone mineral density (BMD) is higher in patients with osteoarthritis $(\mathrm{OA})$, while other studies do not agree. Our aim was to examine the cross-sectional association between phalangeal BMD and radiographic knee OA.

Methods: A total of 2855 participants were included in this study. Radiographic knee OA was defined as KellgrenLawrence (K-L) Grade $\geq 2$ in at least one leg. BMD scans of the middle phalanges of the second, third and fourth digits of the nondominant hand were performed with a compact radiographic absorptiometry system (Alara MetriScan ${ }^{\oplus}$ ). A multivariable logistic analysis model was applied to test the relation between phalangeal BMD with radiographic knee $\mathrm{OA}$, the presence of knee osteophytes (OSTs), and knee joint space narrowing (JSN) after adjusting for a number of potential confounding factors.

Results: The multivariable-adjusted odds ratios with $95 \%$ confidence intervals [ORs (95\% Cl)] of radiographic knee OA across phalangeal BMDs were 1.08 (95\% Cl 0.89-1.32) and 0.62 (95\% Cl 0.45-0.86), respectively. The P for trend was 0.09 . For the female population, the multivariable-adjusted ORs ( $95 \% \mathrm{Cl}$ ) of radiographic knee OA across phalangeal BMD were 1.01 (95\% Cl 0.73-1.37) and 0.58 (95\% Cl $0.38-0.87$ ), respectively. The P for trend was 0.02 . This positive finding, however, did not exist in the male subgroup. There was a significantly lower prevalence of OST in the osteoporosis (OP) group than in the normal group ( $\mathrm{OR}=0.59,95 \% \mathrm{Cl} 0.40-0.88$; $\mathrm{P}$ for trend was 0.01). In contrast, the prevalence of JSN was significantly higher in the osteopenia group $(\mathrm{OR}=1.22,95 \% \mathrm{Cl} 1.00-1.48)$ and the $\mathrm{OP}$ group $(\mathrm{OR}=1.35,95 \% \mathrm{Cl}$ $1.00-1.84)$ than in the normal group. The P for trend was 0.02 .
\end{abstract}

Conclusions: This study observed lower odds for the presence of radiographic knee OA and OST in OP patients than in normal subjects. The prevalence of JSN was higher in the osteopenia and OP groups than in normal subjects.

Keywords: Osteoarthritis, Knee, Phalangeal, Bone mineral density, Kellgren-Lawrence grade

\section{Background}

Osteoarthritis (OA), the most prevalent joint disease, is characterized by progressive loss of articular cartilage, which leads to chronic pain and functional restrictions in affected joints. Worldwide estimates are that about $10 \%$ of men and $18 \%$ of women and about $60-65 \%$ of those $>60$ years of age have symptomatic OA and $80 \%$ of them have movement limitations [1]. Likewise, the prevalence of .osteoporosis (OP) increases with age. OP

\footnotetext{
* Correspondence: Igh9640@sina.cn

${ }^{\dagger}$ Equal contributors

'Department of Orthopaedics, Xiangya Hospital, Central South University, No.87 Xiangya Road, Changsha, Hunan Province 410008, China

Full list of author information is available at the end of the article
}

is a metabolic bone disease characterized by abnormalities in the amount and microarchitectural arrangement of bone tissue that could lead to enhanced bone fragility and a consequent increase in fracture risk [2]. The lifetime risk of a hip fracture from age 50 years onward has been estimated at $17 \%$ for white women and $6 \%$ for white men in the United States [3]. The association between $\mathrm{OA}$ and $\mathrm{OP}$ has remained controversial since the release of the first research outcome 40 years ago, which indicated an apparent inverse relation between these two common diseases [4]. To date, no consensus has been reached. 
Both OA and OP are multifactorial diseases and are influenced by genetics, external environment, the endocrine system, metabolism, biomechanics and trauma [5-9]. Although OA and OP are generally considered different diseases, they share several of the same risk factors, such as bone, cartilage metabolism, aging, sex, and timing of menopause [8-12]. These two common age-related disorders can cause impairment of activities of daily life and quality of life, leading to increased morbidity and mortality among the elderly.

The advent of precise, accurate measurements of bone mass and density has given researchers tools to examine the relation between OA and OP relative to bone [13]. Bone mass change is reflected in bone mineral density (BMD). According to the World Health Organization (WHO), BMD measurement has been considered the gold standard for diagnosing OP [14]. Patients with OA have been considered to have an elevated BMD [15-20], as it has long been hypothesized that systemic or local bone BMD is involved in the pathogenesis of cartilage degradation [21, 22]. Previous studies have indicated that patients with OA of the knee were more likely to have greater bone mass than normal subjects or those with OP. In fact, their BMD was found to be elevated in the spine [23, 24], femoral neck [22, 25], forearm [26, 27], and knee $[28,29]$. Other studies, however, indicated that, despite a higher than average bone mass, women with greater joint OA do not have the reduced risk of fracture that a higher bone mass should confer [30, 31]. Some even found lower BMD at the affected sites [32, 33]. These arguments lead to the assumption that the relation between BMD and OA is complicated and may differ by sites or stages. Based on measurements of phalangeal BMD and radiographic knee OA in a large number of apparently healthy Chinese subjects, this cross-sectional study aimed to examine whether the positive association between phalangeal BMD and radiographic knee OA exists in a Chinese population.

\section{Methods}

\section{Study population}

The Xiangya Hospital Health Management Center Study (XYHMCS) included a cohort consisting mainly of apparently healthy Chinese people from the general public who were undergoing health screening. The study design has been published elsewhere [34]. Data were collected from 2855 participants (1609 men, 1246 women) who voluntarily underwent a routine comprehensive health checkup at the Department of Health Examination Center Xiangya Hospital, Central South University in Changsha, Hunan Province, China from October 2013 to July 2014. Registered nurses interviewed all participants during the examination process using standard questionnaires, aiming to gather information on demographic characteristics and health-related habits. Inclusion criteria were as follows: (1) $\geq$ aged 40 years; (2) were members of general public; (3) had undergone the weight-bearing bilateral anteroposterior radiography of the knee and non-dominant hand BMD test; (4) had completed the semi-quantitative Food Frequency Questionnaire (FFQ) about the average consumption of foods and drinks over the past year; (5) had all basic characteristics, such as age, sex, body mass index (BMI), and smoking status. Initially, this cross-sectional study included 4622 participants who underwent weight-bearing bilateral anteroposterior radiography of the knee and no-dominant hand BMD test. Then, we excluded all individuals with radiographic evidence of other joint diseases such as osteochondroma or fracture $(n=105)$, those who did not complete the FFQ $(n=1528)$, and those $<40$ years $(n=134)$.

The ethics committee of Xiangya Hospital of Central South University approved this study. All participants gave written informed consent at the time of recruitment.

\section{Radiographic assessment of knee OA}

Subjects had weightbearing semi-flexed posteroanterior and lateral view knee radiographs obtained using a standard, validated protocol $[35,36]$. Two orthopedists, without knowledge of the participants' clinical symptoms independently assessed all radiographs using the Kellgren - Lawrence (K - L) radiographic atlas [37]. Disagreements between the two orthopedists were resolved by discussion. If at least one knee joint was graded as $\mathrm{K}-\mathrm{L} \geq 2$, the participant was diagnosed with radiographic knee OA.

Interrater reliability was calculated based on 40 random radiographs assessed by two orthopedists. Intrarater reliability was calculated based on the 40 random radiographs measured by one orthopedist, with each radiograph assessed twice, independently. The reliability of the measurements were examined using the kappa (к) test. Interrater and intrarater reliability were both satisfied ( $\kappa=0.85$ and 0.68 , respectively). In addition, joint space narrowing (JSN) and osteophytes (OSTs) were assessed individually based on a scale of $0-3(0=$ normal, $3=$ most severe) according to the Osteoarthritis Research Society International atlas [38]

\section{BMD measurement}

BMD measurement is a universal method for arriving at an early diagnosis of OP. In this study, BMD was measured at the middle phalanges of the second to fourth fingers on the no-dominant hand using a compact radiographic absorptiometry system (Alara MetriScan; ${ }^{\circ}$ Alara Inc., Fremont, CA, USA). Participants were asked to place the non-dominant hand on the molded support plate with all ornaments removed. BMD was recorded in arbitrary units (mineral mass/area) and in grams per square centimeter $\left(\mathrm{g} / \mathrm{cm}^{2}\right)$. 
our staff only recorded data of people who are osteopenia or OP in order to inform patients their illness. But the data of normal BMD people wasn't recorded.

T-scores were calculated based on the group ages according to a standard BMD database provided by the manufacturer containing data on healthy controls and ages in years. Specifically, T-scores were derived from the reference database by comparing the measured BMD with the average BMD for healthy subjects of the same sex and age. According to the WHO, BMD levels within 1 standard deviations (SD) of a normal young adult are considered normal. Osteopenia (low bone mass) refers to the condition where the BMD level is 1.0-2.5 SD below that of a normal young adult. OP refers to the condition where the BMD level is $\geq 2.5 \mathrm{SD}$ below normal [39].This peripheral densitometry device has advantages, including low cost, efficiency, portability and low X-ray dose $(<0.02 \mu \mathrm{SV}$ per examination), making it suitable for epidemiological screening. The mean coefficient of variation of this method was $1.7 \%$ [40]. Normal BMD normal is defined as a BMD within $1 \mathrm{SD}$ of the young adult reference mean [14]. In this study, the control group was defined as the reference.

\section{Assessment of dietary and non-dietary exposures}

A semi-quantitative FFQ (SFFQ) especially designed for the population in Hunan province of China was used to evaluate dietary intake. This SFFQ contains 63 food items that are commonly consumed in Hunan province. Participants were required to answer the frequency-never, once per month, two to three times per month, one to three times per week, four to five times per week, once per day, twice per day, or three times or more per day-they consumed each food item and the average amount they consumed for each time $(<100 \mathrm{~g}, 100-200 \mathrm{~g}, 201-300 \mathrm{~g}, 301-400 \mathrm{~g}$, $401-500 \mathrm{~g}, \geq 500 \mathrm{~g})$ during the past year. To help them make choices more easily and accurately, colored pictures showing food samples with labeled weights were provided. The validity of the SFFQ was tested by comparing it with the 24-h dietary recall method for a similar population. The Chinese Food Composition Table was referenced to calculate the individual composition of macronutrients and micronutrients of the included foods [41]. This SFFQ has been validated and was used in a previously published study [42]. The weight and height of each subject were measured to calculate the BMI. People with BMI $\geq 25 \mathrm{~kg} / \mathrm{m}^{2}$ were defined as overweight. [43] The smoking status, alcohol drinking status, and use of calcium supplements were established by direct faceto-face questioning.

\section{Statistical analysis}

The continuous data were expressed as means $\pm \mathrm{SD}$, and the categorical data were expressed in percentages. The OP status was classified into three levels: normal, osteopenia and OP. Differences in continuous data were evaluated by the one-way classification analysis of variance (normally distributed data) or the Kruskal-Wallis $\mathrm{H}$ test (non-normally distributed data). Differences in qualitative data were assessed by the $\chi^{2}$ test. The relation between $\mathrm{OA}$ and BMD was determined by the liner trend $\chi^{2}$ test, and evaluated using multivariable logistic regression. Associations between each $\mathrm{OP}$ status and OA were adjusted for the following variables: sex, age, BMI, smoking status, alcohol drinking status, activity level, mean total energy intake, mean $\mathrm{Ca}$ intake, and $\mathrm{Ca}$ supplementation. A test for linear trend was conducted by putting the BMD status as ranked data into the Logistic regression model. All statistical analyses were performed in both subgroups stratified by sex.

Associations between phalangeal BMD and JSN, phalangeal BMD and OST, and OP status and OA were also evaluated by conducting a multivariable logistic regression. Data analyses were performed using SPSS 17.0 (SPSS, Chicago, IL, USA). $P<0.05$ was considered to indicate statistical significance.

\section{Results}

Tables 1 and 2 present the basic characteristics of the study population according to their OP and OA status. The overall prevalence of radiographic knee OA of the subjects in this cross-sectional study (aged $\geq 40$ years) was $29.2 \%$ (30.0 \% in men, $28.1 \%$ in women). Significant differences were observed across different BMD statuses for age, sex ratio, BMI, smoking status, alcohol drinking status, mean total energy intake, mean $\mathrm{Ca}$ intake, and use of $\mathrm{Ca}$ supplements.

Significant differences were observed between different OA status levels for age and Ca supplements use. Univariate analysis indicated that there was a significant association between phalangeal BMD and OA $(\mathrm{p}=0.01)$. The multivariable model was adjusted for sex, age, BMI, smoking status, alcohol drinking status, activity level, mean total energy intake, mean Ca intake, and Ca supplementation. The multivariable-adjusted odds ratios with $95 \%$ confidence interval [OR $(95 \% \mathrm{CI})$ ] of radiographic knee OA across phalangeal BMD were 1.08 (95\% CI 0.89-1.32) and 0.62 (95 \% CI 0.45-0.86), respectively. The P for trend was 0.09 (Table 3). For the female subgroup, the multivariable-adjusted ORs (95\% $\mathrm{CI}$ ) of radiographic knee $\mathrm{OA}$ across phalangeal $\mathrm{BMD}$ were 1.01 (95 \% CI 0.73-1.37) and 0.58 (95 \% CI $0.38-$ 0.87 ), respectively (Table 3 ). The $\mathrm{P}$ for trend was 0.02 . This positive finding, however, did not exist in the male subgroup. Furthermore, for the $\mathrm{BMI}<25 \mathrm{~kg} / \mathrm{m}^{2}$ 
Table 1 Characteristics among 2855 participants according to status of OP

\begin{tabular}{|c|c|c|c|c|}
\hline \multirow[t]{2}{*}{ Characteristics } & \multicolumn{3}{|l|}{ Status of OP } & \multirow[t]{2}{*}{$P$} \\
\hline & Normal & Osteopenia & $\mathrm{OP}$ & \\
\hline N & 1803 & 786 & 266 & - \\
\hline OA (\%) & 26.8 & 34.2 & 30.1 & 0.01 \\
\hline Age (years) & $50.6 \pm 6.3$ & $54.4 \pm 7.4$ & $59.5 \pm 6.8$ & $<0.001$ \\
\hline Female (\%) & 36.5 & 45.5 & 86.5 & $<0.001$ \\
\hline BMI $\left(\mathrm{kg} / \mathrm{m}^{2}\right)$ & $24.7 \pm 3.4$ & $24.3 \pm 3.1$ & $23.6 \pm 3.1$ & $<0.001$ \\
\hline Overweight (\%) & 44.0 & 38.3 & 30.5 & $<0.001$ \\
\hline Smoking (\%) & 28.1 & 25.2 & 7.9 & $<0.001$ \\
\hline Alcohol drinking (\%) & 42.1 & 32.3 & 16.2 & $<0.001$ \\
\hline Mean total energy intake (kcal/d) & $1664.1 \pm 774.2$ & $1600.7 \pm 732.4$ & $1408.4 \pm 546.6$ & $<0.001$ \\
\hline Mean Ca intake (kcal/d) & $507.9 \pm 346.0$ & $492.6 \pm 308.4$ & $431.8 \pm 253.8$ & $<0.001$ \\
\hline Ca supplementation (\%) & 24.3 & 28.4 & 47.0 & $<0.001$ \\
\hline
\end{tabular}

$N$ number, $O A$ osteoarthritis, $O P$ osteoporosis, $B M I$ body mass index, $C a$ calcium

subgroup, the multivariable-adjusted ORs (95\% CI) of radiographic knee $\mathrm{OA}$ across phalangeal BMD were 0.97 (95\% CI 0.76-1.25) and 0.56 (95\% CI 0.37-0.84), respectively (Table 3 ). The $\mathrm{P}$ for trend was 0.03 . This positive finding, however, did not exist in the $\mathrm{BMI} \geq 25 \mathrm{~kg} /$ $\mathrm{m}^{2}$ subgroup.

Multivariable-adjusted relations of phalangeal BMD with JSN and OST are show in Table 4. There was a significantly lower prevalence of OSTs in the OP group than in the no-OP group $(\mathrm{OR}=0.59,95 \% \mathrm{CI} 0.40-0.88$; $\mathrm{P}$ for trend was 0.01). In contrast, the prevalence of JSN was significantly higher in the osteopenia and OP groups than in the no-OP group (osteopenia: $\mathrm{OR}=1.22,95 \%$ CI 1.00-1.48; OP: OR $=1.35,95 \%$ CI 1.00-1.84). The P for trend was 0.02 .

Multivariable-adjusted relations of $\mathrm{OP}$ and radiographic knee OA reveals the multivariable-adjusted association of OP and radiographic knee OA. The outcome suggests a negative association between $\mathrm{OP}$ and $\mathrm{OA}$ $(\mathrm{OR}=0.60,95 \% \mathrm{CI} 0.44-0.82, \mathrm{P}=0.001)$ (Additional file $1)$.

\section{Discussion}

The present study showed that the overall prevalence of definitive radiographic knee OA was $29.2 \%$ (30.0\% in men, $28.1 \%$ in women). We found lower odds for the appearance of radiographic knee OA and OST in OP patients than in those with normal knees. The prevalence of JSN was higher in patients with osteopenia and OP than in normal subjects.

As far as we know, this is the first study that has evaluated phalangeal BMD in relation to radiographic knee OA with adjustment of various factors for the Chinese population. In line with most previous research findings, this study observed lower odds for the presence of radiographic knee OA and OST in OP patients than in

Table 2 Characteristics among 2855 participants according to status of OA

\begin{tabular}{llll}
\hline Characteristics & \multicolumn{2}{l}{ Status of OA } & \multicolumn{1}{l}{ OA } \\
\cline { 2 - 3 } Normal & Nor & 833 & - \\
OP (\%) & 2022 & 9.6 & 0.74 \\
Age (years) & 9.2 & $55.1 \pm 7.8$ & $<0.001$ \\
Female (\%) & $51.4 \pm 6.7$ & 42.0 & 0.26 \\
BMl (kg/m $\left.{ }^{2}\right)$ & 44.3 & $24.5 \pm 3.2$ & 0.87 \\
Overweight (\%) & $24.5 \pm 3.2$ & 42.0 & 0.55 \\
Smoking (\%) & 40.8 & 24.8 & 0.67 \\
Alcohol drinking (\%) & 25.6 & 36.0 & 0.49 \\
Mean total energy intake (kcal/d) & 37.4 & $1610.1 \pm 800.3$ & 0.64 \\
Mean Ca intake (kcal/d) & $1628.1 \pm 725.2$ & $490.9 \pm 294.5$ & 0.82 \\
Ca supplementation (\%) & $498.9 \pm 342.2$ & 30.6 & 0.02 \\
\hline
\end{tabular}

$N$ number, $O A$ osteoarthritis, $O P$ osteoporosis, $B M I$ body mass index, $C a$ calcium 
Table 3 Multivariable-adjusted relations of phalangeal BMD and radiographic knee OA $(n=2855)$

\begin{tabular}{|c|c|c|c|c|}
\hline & \multicolumn{3}{|l|}{ Status of OP } & \multirow[b]{2}{*}{$P$ for trend } \\
\hline & Normal & Osteopenia & $\mathrm{OP}$ & \\
\hline Participants (n) & 1803 & 786 & 266 & - \\
\hline Knee OA (n) & 484 & 269 & 80 & - \\
\hline Multivariable-adjusted OR & 1.00 (Reference) & $1.08(0.89-1.32)$ & $0.62(0.45-0.86)$ & 0.09 \\
\hline \multicolumn{5}{|l|}{ Male subgroup } \\
\hline Multivariable-adjusted OR & 1.00 (Reference) & $1.14(0.89-1.46)$ & $0.74(0.34-1.59)$ & 0.67 \\
\hline \multicolumn{5}{|l|}{ Female subgroup } \\
\hline Multivariable-adjusted OR & 1.00 (Reference) & $1.01(0.73-1.37)$ & $0.58(0.38-0.87)$ & 0.02 \\
\hline \multicolumn{5}{|l|}{$\mathrm{BMI}<25 \mathrm{~kg} / \mathrm{m}^{2}$ subgroup } \\
\hline Multivariable-adjusted model & 1.00 (Reference) & $0.97(0.76-1.25)$ & $0.56(0.37-0.84)$ & 0.03 \\
\hline \multicolumn{5}{|l|}{$\mathrm{BMI} \geq 25 \mathrm{~kg} / \mathrm{m}^{2}$ subgroup } \\
\hline Multivariable-adjusted OR & 1.00 (Reference) & $1.26(0.93-1.70)$ & $0.78(0.45-1.34)$ & 0.84 \\
\hline
\end{tabular}

$O A$ osteoarthritis, $O P$ osteoporosis, $B M I$ body mass index

*The multivariable-adjusted model was adjusted for sex, age, BMI, smoking status, alcohol drinking status, activity level, mean total energy intake, mean Ca intake, as well as Ca supplementation. The prevalence of osteopenia and OP in overweight (BMI $\geq 25 \mathrm{~kg} / \mathrm{m} 2$ ) population was $25.6 \%$ and $6.9 \%$, respectively

normal knee subjects independent of certain confounding factors, such as sex, age, BMI, smoking, alcohol drinking, activity level, mean total energy intake, mean $\mathrm{Ca}$ intake, and $\mathrm{Ca}$ supplementation. The proportion of overweight men was higher than that of overweight women ( $45.8 \%$ vs. $35.5 \%, P<0.001)$, which may be the main reason why the prevalence of knee OA was similar in men and women in this population.

A report from Global Adult Tobacco Survey showed that the overall cigarette smoking rate of the Chinese population $>15$ years of age is $28.1 \%$, including $52.9 \%$ of the male population and $2.4 \%$ of the female population [44]. The WHO estimated that, globally, about $53 \%$ of people aged $\geq 15$ years have ever consumed alcohol, and that alcohol consumption is generally more prevalent among men [45]. As there is a significantly higher male ratio in the no-OP group than in the OP group, it makes sense that the prevalence of smoking and alcohol drinking is higher in the former group. The prevalence of OA was supposed to be the highest in the no-OP group as people with low BMD are less likely to suffer from OA. However, we observed that the age in the noOP group was much younger than osteopenia and OP group, which might explain why the prevalence of $\mathrm{OA}$ was the lowest in this group.

BMD measurement at the hip and spine with dualenergy X-ray absorptiometry (DXA) is considered the gold standard for diagnosing OP $[14,46]$. However, it is a very expensive method that requires frequent calibration to work properly, so it is not always available in developing countries. Using radiographic absorptiometry (RA) (MetriScan) and DXA (Hologic 4500-A; Hologic Inc., Waltham, Mass., USA), Hansen measured the BMD of the intermediate phalanges of the second to fourth fingers, the lumbar spine (L2-L4), and the total hip in 218 men aged 60-74 years (mean 68.8 years). He concluded that RA has moderate ability to identify osteoporotic individuals. RA, however, may be used as a prescreening tool for men because it could rule out the diagnosis in half the population at little cost [47]. In comparison with DXA as demonstrated by Daniel, this methodology is less expensive, portable, versatile, and

Table 4 Multivariable-adjusted relations of phalangeal BMD with JSN and OST ( $n=2855$ )

\begin{tabular}{lllll}
\hline & Status of OP & & & OP \\
\cline { 2 - 4 } & Normal & Osteopenia & 266 & P for trend \\
\hline Participants (n) & 1803 & 786 & 60 & - \\
OST (n) & 195 & 122 & $0.59(0.40,0.88)$ & - \\
Multivariable-adjusted OR & 1.00 (Reference) & $0.85(0.65,1.12)$ & 102 & - \\
JSN (n) & 444 & 245 & $1.35(1.00,1.84)$ & 0.01 \\
Multivariable-adjusted OR & 1.00 (Reference) & $1.22(1.00,1.48)$ & \\
\hline
\end{tabular}

OP osteoporosis, OST Osteophyte, JSN joint space narrowing

*The multivariable-adjusted model was adjusted for sex, age, BMI, smoking status, alcohol drinking status, activity level, mean total energy intake, mean Ca intake, as well as Ca supplementation 
accurate for studying changes in the density of materials [48]. The efficacy of phalangeal BMD RA, when using the same device, has been studied by several authors in different cohorts [49-51].

There are several explanations for the lower odds for the presence of radiographic knee OA and OST in OP patients. BMD reflects the quality of bone. A high BMD indicates increased bone quality, which in turn could reduce the fracture risk in patients with OP. Nevitt's study proved the existence of an association between OSTs and femoral BMD [52]. Both OSTs and bone density can be explained by bone formation. This theory suggests that high BMD is "bone formers" and shows a trend of OSTs formation, whereas low BMD levels are perhaps "bone absorbers" and may cause bone mass loss [53, 54]. Highly increased periarticular bone mass may increase the mechanical stress on cartilage and hence increase the risk of OA [55].

General factors may also play a role in OA as the disease often affects more than a single joint. Dequeker measured iliac crest bone of patients with hand OA and found that elevated serum insulin-like growth factor I (IGF-1) could stimulate OST formation. Therefore, he concluded that insulin might have an anabolic effect on bone, leading to high BMD [56]. In our study, the prevalence of JSN was greater in osteopenia and OP groups than in the no-OP group. This is in accord with Ding's results, who also found JSN in both hips and knees in association with greater total-hip bone loss [57]. The mechanisms for the associations among JSN, OSTs, and bone loss are unclear. They were all adjusted for BMI, sex, age, activity level, and vitamin D status, suggesting that they may be independent of these common risk factors that are shared by OA and OP.

Summarizing previous studies, high bone mass in OA patients may be caused by multiple factors, including genetic factors, common risk factors, the role of subchondral bone in cartilage damage, actions of growth factors, such as IGF - I and IGF - II, and transforming growth factor $\beta$. In this study, with adjustments for age, height, body weight, BMI and so on, the significance was also observed in women with OA of the knee. Therefore, the above factors, in addition to common risk factors (e.g., high body weight or obesity), may contribute to the high BMD in patients with OA of the knee, although their specific relation with BMD have not yet been identified. Further studies may be needed to clarify the uncertainty.

The findings of this study have demonstrated a significant association between elevated metacarpal BMD and radiographic knee OA in the female subgroup, but not in the male subgroup. The reason for the apparent sex difference is still unclear. It may be due to dissimilar risk factor profiles for knee OA. That is, women may be more affected by metabolic factors and men by joint injuries. This study also shows that women with significantly increased BMD-considered to be a protective factor for $\mathrm{OP}-$ have a greater chance of developing OA. Higher BMD means that the weight-bearing joints may suffer from heavier impact and pressure, so the cartilage is more likely to be damaged [58]. The present study also indicated a significant association between elevated metacarpal BMD and radiographic knee $\mathrm{OA}$ in the normal-weight subgroup, but not in those who are overweight. The reason is not discussed in this study, and further exploration is needed.

Limitations of the present study should also be acknowledged. First, the cross-sectional design of this study precluded causal relationships. Thus, further prospective studies should be carried out to establish a causal association between OA and OP. Second, as our study based on health examination, we only recorded BMD of people who are osteopenia or OP, leaving those with normal BMD unrecorded. But it did not affect data analysis. Another limitation of this study lies in the relatively small sample size of some subgroup analyses. Future research with a larger sample size is needed to confirm the subgroup analysis findings obtained here.

\section{Conclusions}

This study observed lower odds for the presence of radiographic knee OA and OST in OP patients than in normal subjects. The prevalence of JSN was higher in the osteopenia and OP groups than in normal subjects.

\section{Additional file}

Additional file 1: Table S1. Multivariable-adjusted relations of phalangeal BMD with OA, JSN and OST in osteopenia and osteoporosis population ( $\mathrm{n}=1052)$. (DOCX $14 \mathrm{~kb})$

\section{Abbreviations \\ ADL: Activities of daily life; BMD: Bone mineral density; BMI: Body mass index; Ca: Calcium; CV: Coefficient of variation; DXA: Dual energy X-ray absorption- metry; FFQ: Food frequency questionnaire; ICC: Intraclass correlation coefficient; IGF: Insulin-like growth factor; K-L: Kellgren-Lawrence; OA: Osteoarthritis; OP: Osteoporosis; QOL: Quality of life; RA: Radiographic absorptiometry; SD: Standard deviations; TGF: Transforming growth factor; SFFQ: Semi-quantitative FFQ; XYHMCS: Xiangya Hospital Health Management Center Study.}

\section{Competing interests}

These authors declared that they have no competing interests.

\section{Authors' contributions}

ZD study design, data collection and analyses, manuscript preparation. CZ study design, data collection and analyses, manuscript preparation. YL data acquisition, manuscript preparation. TY data acquisition, manuscript preparation. HL data acquisition, manuscript preparation. JW data acquisition, manuscript preparation. GHL study design, data analyses, manuscript preparation. All authors read and approved the final manuscript. 


\section{Acknowledgments}

This work was supported by the Hunan Provincial Innovation Foundation for Postgraduate (CX2014A005), the National Natural Science Foundation of China (No. 81201420, 81272034, 81472130, 81501923), the Provincial Science Foundation of Hunan (No. 14JJ3032), the Scientific Research Project of the Development and Reform Commission of Hunan Province ([2013]1199), the Scientific Research Project of Science and Technology Office of Hunan Province (2013SK2018), the Doctoral Scientific Fund Project of the Ministry of Education of China (20120162110036).

\section{Author details}

'Department of Orthopaedics, Xiangya Hospital, Central South University, No.87 Xiangya Road, Changsha, Hunan Province 410008, China. ${ }^{2}$ Health Management Center, Xiangya Hospital, Central South University, Changsha, Hunan Province 410008, China. ${ }^{3}$ Department of Epidemiology and Health Statistics, School of Public Health, Central South University, Changsha, Hunan Province 410008, China.

\section{Received: 14 July 2015 Accepted: 3 February 2016}

\section{Published online: 11 February 2016}

\section{References}

1. Glyn-Jones S, Palmer AJ, Agricola R, Price AJ, Vincent TL, Weinans H, et al. Osteoarthritis. Lancet. 2015;386(9991):376-87.

2. Curtis EM, Moon RJ, Dennison EM, Harvey NC, Cooper C. Recent advances in the pathogenesis and treatment of osteoporosis. Clin Med. 2015;15 Suppl 6:592-6.

3. Kim BH, Lee $S, Y o o$ B, Lee WY, Lim Y, Kim MC, et al. Risk factors associated with outcomes of hip fracture surgery in elderly patients. Korean J Anesthesiol. 2015;68(6):561-7.

4. Consensus development conference: diagnosis, prophylaxis, and treatment of osteoporosis. Am J Med. 1993;94(6):646-50

5. Marcucci G, Brandi ML. Rare causes of osteoporosis. Clin Cases Miner Bone Metab. 2015;12(2):151-6.

6. Herrero-Beaumont G, Roman-Blas JA, Largo R, Berenbaum F, Castaneda S. Bone mineral density and joint cartilage: four clinical settings of a complex relationship in osteoarthritis. Ann Rheum Dis. 2011:70(9):1523-5.

7. Ryd L, Brittberg M, Eriksson K, Jurvelin JS, Lindahl A, Marlovits S, et al. PreOsteoarthritis: Definition and Diagnosis of an Elusive Clinical Entity. Cartilage. 2015;6(3):156-65

8. Johnson VL, Hunter DJ. The epidemiology of osteoarthritis. Best Pract Res Clin Rheumatol. 2014;28(1):5-15.

9. Leslie WD, Morin SN. Osteoporosis epidemiology 2013: implications for diagnosis, risk assessment, and treatment. Curr Opin Rheumatol. 2014;26(4):440-6.

10. Gossan N, Boot-Handford R, Meng QJ. Ageing and osteoarthritis: a circadian rhythm connection. Biogerontology. 2015;16(2):209-19.

11. Ferencz V, Horvath C, Huszar S, Bors K. Assessment of risk factors for fractures in postmenopausal women with osteoporosis. Orv Hetil. 2015: 156(4):146-53.12.

12. Wang DM, Zeng QY, Chen SB, Gong Y, Hou ZD, Xiao ZY. Prevalence and risk factors of osteoporosis in patients with ankylosing spondylitis: a 5-year follow-up study of 504 cases. Clin Exp Rheumatol. 2015;33(4):465-70.

13. Dequeker J. Inverse relationship osteoarthritis-osteoporosis: what is the evidence? What are the consequences? Br J Rheumatol. 1996;35(9):813-20.

14. Ito M. Absolute risk for fracture and $\mathrm{WHO}$ guideline. Recent interest in bone quality. Clin Calcium. 2007;17(7):1066-70.

15. Dequeker J, Aerssens J, Luyten FP. Osteoarthritis and osteoporosis: clinical and research evidence of inverse relationship. Aging Clin Exp Res. 2003; 15(5):426-39.

16. Flugsrud GB, Nordsletten L, Espehaug B, Havelin LI, Engeland A, Meyer HE. The impact of body mass index on later total hip arthroplasty for primary osteoarthritis: a cohort study in 1.2 million persons. Arthritis Rheum. 2006; 54(3):802-7.

17. Jarvholm B, Lewold S, Malchau H, Vingard E. Age, bodyweight, smoking habits and the risk of severe osteoarthritis in the hip and knee in men. Eur Epidemiol. 2005;20(6):537-42.

18. Reijman M, Pols HA, Bergink AP, Hazes JM, Belo JN, Lievense AM, et al. Body mass index associated with onset and progression of osteoarthritis of the knee but not of the hip: the Rotterdam Study. Ann Rheum Dis. 2007;66(2):158-62.

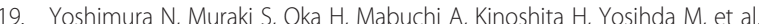
Epidemiology of lumbar osteoporosis and osteoarthritis and their causal relationship-is osteoarthritis a predictor for osteoporosis or vice versa?: the Miyama study. Osteoporos Int. 2009;20(6):999-1008.

20. Okano K, Ito M, Aoyagi K, Osaki M, Enomoto H, Yamaguchi K. Discrepancy in bone mineral densities at different skeletal sites in hip osteoarthritis patients. Mod Rheumatol. 2014;24(2):340-2.

21. Guler-Yuksel M, Bijsterbosch J, Allaart CF, Meulenbelt I, Kroon HM, Watt I. Accelerated metacarpal bone mineral density loss is associated with radiographic progressive hand osteoarthritis. Ann Rheum Dis. 2011;70(9): 1625-30.

22. Bergink AP, Uitterlinden AG, Van Leeuwen JP, Hofman A, Verhaar JA, Pols HA. Bone mineral density and vertebral fracture history are associated with incident and progressive radiographic knee osteoarthritis in elderly men and women: the Rotterdam Study. Bone. 2005:37(4):446-56.

23. Povoroznyuk V, Lamy O, Dzerovych N, Hans D. Trabecular bone score and BMD of lumbar spine in healthy women: Pros and cons. Osteoporos Int. 2013;24(1):S244

24. Im Gl, Kwon OJ, Kim CH. The relationship between osteoarthritis of the knee and bone mineral density of proximal femur: A cross-sectional study from a Korean population in women. CiOS Clin Orthop Surg. 2014:6(4):420-5.

25. Bischoff-Ferrari HA, Zhang Y, Kiel DP, Felson DT. Positive association between serum 25-hydroxyvitamin d level and bone density in osteoarthritis. Arthritis Rheum. 2005;53(6):821-6.

26. Iwamoto J, Takeda T, Ichimura S. Forearm bone mineral density in postmenopausal women with osteoarthritis of the knee. J Orthop Sci. 2002; 7(1):19-25.

27. Sudo A, Miyamoto N, Horikawa K. Prevalence and risk factors for knee osteoarthritis in elderly Japanese men and women. J Orthop Sci. 2008;13(5): $413-8$

28. Ichchou L, Allali F, Rostom S, Bennani L, Hmamouchi I, Abourazzak FZ, et al. Relationship between spine osteoarthritis, bone mineral density and bone turn over markers in post-menopausal women. BMC Womens Health. 2010; $10: 25$

29. Burnett WD, Kontulainen SA, McLennan CE, Hazel D, Talmo C, Hunter DJ, et al. Knee osteoarthritis patients with severe nocturnal pain have altered proximal tibial subchondral bone mineral density. Osteoarthritis Cartilage. 2015:23(9):1483-90.

30. Jones G, Nguyen T, Sambrook PN, Lord SR, Kelly PJ, Eisman JA. Osteoarthritis, bone density, postural stability, and osteoporotic fracture: a population based study. J Rheumatol. 1995;22(5):921-5.

31. Arden NK, Nevitt MC, Lane NE, Gore LR, Hochberg MC, Scott JC, et al. Osteoarthritis and the risk of falls, rates of bone loss, and osteoporotic fractures. Arthritis Rheum. 1999;42(7):1378-85.

32. Goerres GW, Häuselmann HJ, Seifert B, Michel BA, Uebelhart D. Patients with knee osteoarthritis have lower total hip bone mineral density in thesymptomatic eg than in the contralateral hip. J Clin Densitom. 2005:8(4):484-7.

33. El-Sherif HE, Kamal R, Moawyah O. Hand osteoarthritis and bone mineral density in postmenopausal women; clinicalrelevance to hand function, pain and disability. Osteoarthritis Cartilage. 2008;16(1):12-7.

34. Zhang Y, Zeng C, Li H, Yang T, Deng ZH, Yang Y, et al. Relationship between cigarette smoking and radiographic knee osteoarthritis in Chinese population: a cross-sectional study. Rheumatol Int. 2015. [Epub ahead of print]

35. Peterfy CG, Li J, Duryea J, Lynch JA, Miaux Y, Genant HK. Nonfluoroscopic method for flexed radiography of the knee that allows reproducible jointspace width measurement. Abstract Arthritis Rheum. 1998;41 Suppl 89:S361.

36. Kothari M, Guermazi A, von Ingersleben G, Miaux Y, Sieffert M, Block JE, et al. Fixed-flexion radiography of the knee provides reproducible joint space width measurements in osteoarthritis. Eur Radiol. 2004;14(9):1568-73.

37. Kellgren JH, Lawrence JS. Radiological assessment of osteoarthrosis. Ann Rheum Dis. 1957;16(2):494-502

38. Assessment of fracture risk and its application to screening for postmenopausal osteoporosis. Report of a WHO Study Group. World Health Organ Tech Rep Ser. 1994:843:1-129.

39. Altman RD, Gold GE. Atlas of individual radiographic features in osteoarthritis, revised. Osteoarthritis Cartilage. 2007:15(Suppl A):A1-56.

40. Matkovic V, Jelic T, Wardlaw GM, Ilich JZ, Goel PK, Wright JK, et al. Timing of peak bone mass in Caucasian females and its implication for the prevention of osteoporosis. Inference from a cross-sectional model. J Clin Invest. 1994; 93(2):799-808.

41. Cheng Y, Dibley MJ, Zhang X, Zeng L, Yan H. Assessment of dietary intake among pregnant women in a rural area of western China. BMC Public Health. 2009:9:222 
42. Wei J, Zeng C, Gong QY, Yang HB, Li XX, Lei GH, et al. The association between dietary selenium intake and diabetes: a cross-sectional study among middle-aged and older adults. Nutr J. 2015;14(1):18.

43. Global Database on Body Mass Index. BMI Classification. World Health Organization. 2006. http://apps.who.int/bmi/index.jsp?introPage=intro_3.html.

44. Giovino GA, Mirza SA, Samet JM, Gupta PC, Jarvis MJ, Bhala N, et al. Tobacco use in 3 billion individuals from 16 countries: an analysis of nationally representative cross-sectional household surveys. Lancet. 2012;380(9842): 668-79.

45. World Health Organisation. Global Status Report on Alcohol and Health. Geneva: World Health Organization; 2014

46. Boot AM, de Ridder AAJ, van der Sluis IM, van Slobbe I, Krenning EP, SMPF d M K-S. Peak bone mineral density, lean body mass and fractures. Bone. 2010;46(2):336-41.

47. Hansen SJ, Nielsen MM, Ryg J, Wraae K, Andersen M, Brixen K. Radiographic absorptiometry as a screening tool in male osteoporosis: results from the odense androgen study. Acta Radiol. 2009:50(6):658-63.

48. Jimenez-Mendoza D, Espinosa-Arbelaez DG, Giraldo-Betancur AL, Hernandez-Urbiola MI, Vargas-Vazquez D, Rodriguez-Garcia ME. Single x-ray transmission system for bone mineral density determination. Rev Sci Instrum. 2011;82(12):125105.

49. Boonen S, Nijs J, Borghs H, Peeters H, Vanderschueren D, Luyten FP. Identifying postmenopausal women with osteoporosis by calcaneal ultrasound, metacarpal digital $\mathrm{x}$-ray radiogrammetry and phalangeal radiographic absorptiometry: a comparative study. Osteoporos Int. 2005; 16(1):93-100.

50. Buch I, Oturai PS, Jensen LT. Radiographic absorptiometry for pre-screening of osteoporosis in patients with low energy fractures. Scand J Clin Lab Invest. 2010;70(4):269-74

51. Thorpe JA, Steel SA. The alara metriscan phalangeal densitometer: evaluation and triage thresholds. Br J Radiol. 2008;81(970):778-83.

52. Nevitt MC, Lane NE, Scott JC, Hochberg MC, Pressman AR, Genant HK, et al. Radiographic osteoarthritis of the hip and bone mineral density. The Study of Osteoporotic Fractures Research Group. Arthritis Rheum. 1995;38(7):907-16

53. Sowers M, Zobel D, Weissfeld L, Hawthorne VM, Carman W. Progression of osteoarthritis of the hand and metacarpal bone loss. A twenty-year followup of incident cases. Arthritis Rheum. 1991:34(1):36-42.

54. Burger $H$, van Daele $P L$, Odding E, Valkenburg HA, Hofman A, Grobbee DE, et al. Association of radiographically evident osteoarthritis with higher bone mineral density and increased bone loss with age. The Rotterdam Study. Arthritis Rheum. 1996;39(1):81-6.

55. Bruyere O, Dardenne C, Lejeune E, Zegels B, Pahaut A, Richy F, et al. Subchondral tibial bone mineral density predicts future joint space narrowing at the medial femoro-tibial compartment in patients with knee osteoarthritis. Bone. 2003;32(5):541-5.

56. Dequeker J, Mohan S, Finkelman RD, Aerssens J, Baylink DJ. Generalized osteoarthritis associated with increased insulin-like growth factor types I and II and transforming growth factor beta in cortical bone from the iliac crest. Possible mechanism of increased bone density and protection against osteoporosis. Arthritis Rheum. 1993;36(12):1702-8.

57. Ding C, Cicuttini F, Boon C, Boon P, Srikanth V, Cooley H, et al. Knee and hip radiographic osteoarthritis predict total hip bone loss in older adults: a prospective study. J Bone Miner Res. 2010;25(4):858-65.

58. Coster MC, Rosengren BE, Karlsson C, von Schevelow T, Magnusson H, Brudin $\mathrm{L}$, et al. Bone mass and anthropometry in patients with osteoarthritis of the foot and ankle. Foot Ankle Surg. 2014;20(1):52-6.

\section{Submit your next manuscript to BioMed Central and we will help you at every step:}

- We accept pre-submission inquiries

- Our selector tool helps you to find the most relevant journal

- We provide round the clock customer support

- Convenient online submission

- Thorough peer review

- Inclusion in PubMed and all major indexing services

- Maximum visibility for your research

Submit your manuscript at www.biomedcentral.com/submit
Biomed Central 